khoa học Đại học Cần Tho. 40 (2015): 115-113.

2. Nguyễn Xuân Long (2009): "Nhu cầu làm thêm của sinh viên trường Đại học Ngoại ngữ - Đại học quốc gia Hà Nô̂i: Thực trạng và giải pháp". Tạp chí Tâm lý hoc. số 9 (126), 9-2009.

3. Trân Thu Hương. Nữ sinh với việc làm thêm.
Khoa tâm lý học, Trường Đại học KHXH và nhân văn - ĐHOG Hà Nội

4. Đinh Thị Mỹ Lệ. Việc làm thêm có ảnh hưởng như thế nào đối với sinh viên duy tân.

5. HSBC Group. Education Market Reports 2018. Trends, Analysis \& Statistics.

\title{
HIÊUU QUẢ BỔ SUNG SŨ̃A BộT HANIE KID LÊN TÌNH TRANG DINH DƯỠNG, SỨC KHỎE VÀ KHẢ NĂNG CHẤP NHÂ̂N SẢN PHẨM CỦA HỌC SINH LỚP MộT
}

\author{
Phạm Quốc Hùng ${ }^{1}$, Trần Đình Thoan ${ }^{2}$, Nguyễn Văn ${ }^{3}$, Trần Thúy Nga
}

\section{TÓM TẮT}

Nghiên cứu có đối chứng, ngẫu nhiên cụm nhằm đánh giá hiệu quả bổ sung "Sản phẩm dinh dưỡng dành cho trè từ 2-10 tuổi Hanie Kid 2+" dạng lên tình trạng dinh dưỡng, sức khỏe và khả năng chấp nhân sản phẩm đối với học sinh lớp một (6-7 tuổi). Nghiển cứu đước hoàn thành tai Thái Bình vào tháng 3/2021 với 55 trẻ nhóm can thiệp bổ sung Sữa bột Hanie Kid 2 lần/ngày trong 2 tháng và 55 trẻ nhóm chứng chế độ ăn thông thường. Kết quả nghiên cứu cho thấy bổ sung Sữa bột Hanie Kid đã có tác động tích cực: cân nặng trung bình tăng $0,5 \mathrm{~kg}(0,86 \pm 0,29 \mathrm{~kg}$ so với $0,36 \pm 0,17 \mathrm{~kg} ; \mathrm{p}<0,01)$; chiêuu cao trung bình tăng $0,29 \mathrm{~cm}(0,88 \pm 0,29 \mathrm{~cm}$ so với $0,59 \pm 0,17 \mathrm{~cm} ; \mathrm{p}<0,05)$; SDD thể nhe cân giảm 10,9\%; nguy cơ SDD nhe cân giảm $14,5 \%$ có ý nghĩa thống kê $(p<0,05)$. Có $x u$ hướng cải thiện tình trạng nhiếm khuẩn hô hấp, tiêu chảy, táo bón, biếng ăn, khó ngủ nhưng số lượng nhỏ, không có ý nghĩa thống kê ( $p>0,05)$.

Từ khóa: đa vi chất, sữa bổ sung, trẻ tiểu học, chiều cao, cân nặng

\section{SUMMARY}

EFFECTS OF HANIE KID FORMULA SUPPLEMENT ON NUTRITION STATUS, HEALTH, AND PRODUCT ACCEPTABILITY OF GRADE ONE STUDENTS

A cluster randomized and controlled study was conducted to evaluate the supplemental effects of "Hanie Kid 2+ formula milk nutrition product" on nutritional status, health and product acceptability for first graders (6-7 years old). The study was completed in Thai Binh in March 2021 with 55 infants supplemented with Hanie Kid Formula Milk 2 times/day for 2 months and 55 control children using

\footnotetext{
${ }^{1}$ Trường Đại học Y Hà Nội

2Trường Đại hoc Y Dước Thái Bình

${ }^{3}$ Trường Cao đẳng Y tế Hà Tình

${ }^{4}$ Viện Dinh dưỡng Quốc gia

Chịu trách nhiệm chính: Phạm Quốc Hùng

Email: phamquochung@hmu.edu.vn

Ngày nhận bài: 13.4.2021

Ngày phản biện khoa học: 25.5.2021

Ngày duyệt bài: 14.6.2021
}

regular diet. Research results showed that Hanie Kid Formula Milk supplementation had positive effects: average weight increased by $0.5 \mathrm{~kg}(0.86 \pm 0.29 \mathrm{~kg}$ vs. $0.36 \pm 0.17 \mathrm{~kg} ; \mathrm{p}<0.01)$; average height increased by $0.29 \mathrm{~cm}(0.88 \pm 0.29 \mathrm{~cm}$ vs. $0.59 \pm 0.17 \mathrm{~cm} ; \mathrm{p}$ $<0.05)$; underweight decreased $10.9 \%$; The risk of underweight malnutrition decreased by $14.5 \%$, with statistically significant $(p<0.05)$. Tendly improve respiratory infections, diarrhea, constipation, anorexia, and difficulty sleeping but having small quantity and not statistically significant $(p>0.05)$.

Keywords: micronutrients, formula milk, primary school student, height, weight

\section{I. ĐẠT VẤN ĐÊ}

Tình trạng suy dinh dưỡng (SDD) nhẹ cân, thấp còi của trẻ em, đặc biệt là vùng nông thôn Việt Nam còn là vấn đề sức khỏe quốc gia ảnh hưởng đến tầm vóc, chiều cao, trí tuê và sức lao động của người Việt và được ngành y tế và Chính phủ đặc biệt quan tâm[1]. Một trong những biện pháp hữu hiệu là sử dụng sữa được bổ sung vi chất dinh dưỡng (VCDD) [2],[3]. Thành phần, hàm lượng, khẩu phần sữa bổ sung cho trẻ em còn là vấn đề tranh luận. "Sản phẩm dinh dưỡng dành cho trẻ từ 2-10 tuổi Hanie Kid 2+" dạng bột (gọi là Sữa bột Hanie Kid) của NutriCare cân đối năng lượng, chất béo, protein, DHA, FOS/Inulin, HMO (2'-FL), Lysin và bổ sung 28 loại vitamin, khoáng chất theo hướng dẫn của WHO [4] hướng tới đối tượng đích là trẻ em lứa tuổi 2-10 tuổi. Nghiên cứu này nhằm đánh giá hiệu quả của Sữa bột Hanie Kid đối với tình trạng dinh dưỡng, sức khỏe và khả năng chấp nhận sản phẩm ở trẻ lớp một (6-7 tuổi).

\section{II. ĐỐI TƯƠNGG VÀ PHƯƠNG PHÁP NGHIÊN CỨU \\ Đối tượng nghiên cứu: trẻ lớp một ở 02} Trường Tiểu học \& Trung học cơ sở thuộc huyện Kiến Xương, tỉnh Thái Bình đáp ứng tiểu chuẩn chấp nhân và loại trừ nghiên cứu. Tiêu chuẩn lựa chọn: Trẻ học lớp một; đang theo học tại trường; không mắc các dị tật bẩm sinh, khuyết 
tật về tâm thần, vận động hoặc trẻ mắc các bệnh mạn tính; được bố mẹ/người giám hộ đồng ý. Tiêu chuẩn loại trừ: đang có bệnh; thừa cân, béo phì (trẻ có WAZ >2 SD, BAZ>1); đang sử dụng các sản phẩm bổ sung dinh dưỡng, đang tham gia một nghiên cứu khác.

Thiết kế nghiên cứu: Nghiên cứu thử nghiệm can thiệp cộng đồng có đối chứng, ngẫu nhiên cưm.

Thời gian: Từ tháng 11/2020 đến 3/2021.

Cỡ mấu, chọn mẫu: Có 210 trẻ lớp một đã được khám sàng lọc và chọn ra 110 trẻ chia vào 2 nhóm can thiệp và nhóm chứng.

Sữa bổ sung: sản xuất bởi Công ty Cổ phần Dinh dưỡng Nutricare có thành phần cho 2 bữa/ngày gồm: năng lượng (400 kcal); chất béo (22g); protein (14g); DHA (36mg); FOS/Inulin $(2,84 \mathrm{~g})$; HMO (2'-FL $(20 \mathrm{mg})$; sữa non $(80 \mathrm{mg})$, IgG $(16 \mathrm{mg})$, Lysin $(760 \mathrm{mg})$ và 14 vitamin: A (1258IU), D3 $(196,8 \mathrm{IU})$, E $(6,52 \mathrm{IU}), \quad \mathrm{K} 1$

\section{KẾT QUẢ NGHIÊN CỨU}

Tổng số có 110 trẻ lớp một tham gia can thiệp gồm 55 trẻ nhóm can thiệp và 55 trẻ nhóm chứng.

Bảng 1. Đặc điểm hai nhóm trước khi can thiệp

\begin{tabular}{|c|c|c|c|}
\hline Chỉ số & Nhóm chứng & Nhóm can thiệp & p \\
\hline Tỷ lế trẻ nam & $49,1 \%$ & $49,1 \%$ & $(\mathrm{a})$ \\
\hline Tuối (tháng) & $76,84 \pm 0,44$ & $76,83 \pm 0,43$ & $>0,05 \mathrm{~b}$ \\
\hline Cân nặng $(\mathrm{kg})$ & $17,94 \pm 1,63$ & $17,91 \pm 1,43$ & $>0,05 \mathrm{~b}$ \\
\hline Chiều cao $(\mathrm{cm})$ & $112,52 \pm 4,22$ & $112,53 \pm 4,0$ & $>0,05 \mathrm{~b}$ \\
\hline SDD thế nhể cân & $10(18,2 \%)$ & $10(18,2 \%)$ & $(\mathrm{a})$ \\
\hline SDD thế thấp còi & $12(21,8 \%)$ & $13(23,6 \%)$ & $>0,05^{\mathrm{c}}$ \\
\hline SDD thế gày còm & $5(9,1 \%)$ & $5(9,1 \%)$ & $\left({ }^{\mathrm{a}}\right)$ \\
\hline Viêm đường hồ hấp cấp & $6(10,9 \%)$ & $5(7,3 \%)$ & $>0,05^{\mathrm{a}}$ \\
\hline Tiêu chảy & $3(5,5 \%)$ & $3(5,5 \%)$ & $>0,05^{\mathrm{b}}$ \\
\hline Táa bón & $4(7,3 \%)$ & $5(9,1 \%)$ & $>0,5^{\mathrm{b}}$ \\
\hline Biếng ăn & $7(12,7 \%)$ & $7(12,7 \%)$ & $>0,5^{\mathrm{b}}$ \\
\hline Khó ngủ & $5(9,1 \%)$ & $6(10,9 \%)$ & $\left({ }^{\mathrm{a}}\right)$ \\
\hline
\end{tabular}

a) không có sự khác biệt hoặc dữ liệu nhỏ thiệp và nhóm chứng về các chỉ số giới, tuối, không làm kiểm định; ' ${ }^{b}$ ) T-test; c) Fisher's exact - test, Bootstrap 1000 samples.

Trước can thiệ, không có sư khác biêt có ý nghĩa thống kê (YNTK) $(p>0,05)$ giữa nhóm can chiêu cao/tuô̂i, BMI/tuổi, tỳ lể SDD các thể nhe cân, thấp còi, gây còm, tỷ lệ các bệnh viêm đường hô hấp, tiêu chảy, táo bón, biếng ăn, khó ngủ.

Bảng 2. Hiệu quả bổ sung Sữa bột Hanie Kid lên tình trạng dỉnh dưỡng

\begin{tabular}{|c|c|c|c|c|}
\hline Chỉ số & Thời gian & $\begin{array}{c}\text { Nhóm chứng } \\
(X \pm S D)\end{array}$ & $\begin{array}{c}\text { Nhóm can thiệp } \\
\bar{X} \pm S D)\end{array}$ & $\mathbf{p}$ \\
\hline \multirow{5}{*}{ Cân nặng (kg) } & T0 & $17,94 \pm 1,63$ & $17,86 \pm 1,39$ & $p>0,05 b$ \\
\hline & T1 & $18,12 \pm 1,61$ & $18,32 \pm 1,34$ & $p>0,05 b$ \\
\hline & T2 & $18,30 \pm 1,58$ & $18,73 \pm 1,29$ & $p<0,05 b$ \\
\hline & T1-T0 & $0,18 \pm 0,10$ & $0,46 \pm 0,16$ & $p<0,05 b$ \\
\hline & T2-T0 & $0,36 \pm 0,17$ & $0,86 \pm 0,29$ & $p<0,01 b$ \\
\hline \multirow{4}{*}{ Chiều cao $(\mathrm{cm})$} & T0 & $112,45 \pm 4,47$ & $112,52 \pm 3,99$ & $p>0,05 b$ \\
\hline & T1 & $112,76 \pm 4,47$ & $113,02 \pm 3,99$ & $p>0,05 b$ \\
\hline & T2 & $113,05 \pm 4,7$ & $113,40 \pm 3,98$ & $p>0,05 b$ \\
\hline & T1-T0 & $0,30 \pm 0,10$ & $0,49 \pm 016$ & $p>0,05 b$ \\
\hline
\end{tabular}




\begin{tabular}{|c|c|c|c|c|}
\hline & T2-T0 & $0,59 \pm 0,17$ & $0,88 \pm 0,29$ & $\mathrm{p}<0,05 \mathrm{~b}$ \\
\hline \multirow{3}{*}{$\begin{array}{c}\text { SDD thể nhe cân } \\
\text { (WAZ<-2SंD) }\end{array}$} & $\mathrm{T} 0$ & $10(18,2 \%)$ & $10(18,2 \%)$ & $\mathrm{a})$ \\
\cline { 2 - 5 } & $\mathrm{T} 1$ & $9(16,4 \%)$ & $6(10,9 \%)$ & $\mathrm{p}>0,05 \mathrm{c}$ \\
\cline { 2 - 5 } & $\mathrm{T} 2$ & $10(18,2 \%)$ & $4(7,3 \%)$ & $\mathrm{p}<0,05 \mathrm{c}$ \\
\cline { 2 - 5 } & $\mathrm{T} 0-\mathrm{T} 2$ & $0(\%)$ & $6(10,9 \%)$ & $\mathrm{p}<0,05 \mathrm{c}$ \\
\hline \multirow{2}{*}{$\begin{array}{c}\text { SDD \& Nguy cơ } \\
\text { SDD thể nhe cân } \\
\text { (WAZ<-1SDD) }\end{array}$} & $\mathrm{T} 0$ & $32(58,2 \%)$ & $36(65,5)$ & $(\mathrm{a})$ \\
\cline { 2 - 5 } & $\mathrm{T} 1$ & $32(58,2 \%)$ & $31(56,4 \%)$ & $\mathrm{p}>0,05 \mathrm{c}$ \\
\cline { 2 - 5 } & $\mathrm{T} 2$ & $32(58,2 \%)$ & $27(49,1 \%)$ & $\mathrm{p}<0,05 \mathrm{c}$ \\
\cline { 2 - 5 } & T0-T2 & $0(0 \%)$ & $8(14,5 \%)$ & $\mathrm{p}<0,05 \mathrm{c}$ \\
\hline
\end{tabular}

a) không có sự khác biệt hoặc dữ liệu nhỏ không làm kiểm định; b) T-test; ${ }^{c}$ ) Fisher's exact - test, Bootstrap 1000 samples.

Tại thời điểm trước can thiệp, không có sự khác biệt về cân nặng, chiều cao giữa 2 nhóm $(p>0,05)$. Tại thời điểm $T 1$, nhóm can thiệp có mức tăng cần tốt hơn nhóm chứng $(0,46 \pm 0,16$ $\mathrm{kg}$ so với $0,18 \pm 0,10 \mathrm{~kg}$ ), chênh lệch $0,28 \mathrm{~kg}$, có YNTK $(p<0,05)$; Tại thời điểm T2, nhóm can thiệp

có mức tăng cân tốt hơn nhóm chứng $(0,86 \pm$ $0,29 \mathrm{~kg}$ so với $0,36 \pm 0,17 \mathrm{~kg})$, chênh lệch $0,5 \mathrm{~kg}$ có YNTK $(p<0,01)$; mức tăng chiều cao $(0,88 \pm$ $0,29 \mathrm{~cm}$ so với $0,59 \pm 0,17 \mathrm{~cm}$ ), chênh lệch $0,29 \mathrm{~cm}$, có YNTK $(p<0,05)$. Tỷ lệ SDD ở nhóm can thiệp giảm rõ rệt so với nhóm chứng: SDD thể nhe cần chênh lệch $10,9 \%$ có YNTK $(p<0,05)$; nguy cơ SDD nhẹ cân chênh lệch $14,5 \%$ có YNTK $(p<0,05)$. Không xuất hiện thừa cân, béo phì.

Bảng 5. Hiệu quả bổ sung Sữa bột Hanie Kid lên tình trạng sức khỏe

\begin{tabular}{|c|c|c|c|c|c|c|}
\hline \multirow{2}{*}{ Chỉ số } & \multicolumn{2}{|c|}{ Trước can thiệp } & \multicolumn{2}{c|}{ Sau CT 1 tháng } & \multicolumn{2}{c|}{ Sau CT 2 tháng } \\
\cline { 2 - 7 } & $\begin{array}{c}\text { Nhóm } \\
\text { chứng }\end{array}$ & $\begin{array}{c}\text { Nhóm can } \\
\text { thiệp }\end{array}$ & $\begin{array}{c}\text { Nhóm } \\
\text { chứng }\end{array}$ & $\begin{array}{c}\text { Nhóm can } \\
\text { thiệp }\end{array}$ & $\begin{array}{c}\text { Nhóm } \\
\text { chứng }\end{array}$ & $\begin{array}{c}\text { Nhóm can } \\
\text { thiệp }\end{array}$ \\
\hline NKHH & $6(10,9 \%)$ & $5(9,1 \%)$ & $5(9,1 \%)$ & $4(7,3 \%)$ & $5(9,1 \%)$ & $3(5,5 \%)$ \\
\hline Tiêu chảy & $3(5,5 \%)$ & $3(5,5 \%)$ & $5(9,1 \%)$ & $3(5,5 \%)$ & $5(9,1 \%)$ & $2(3,6 \%)$ \\
\hline Táo bón & $4(7,3 \%)$ & $5(9,1 \%)$ & $3(5,5 \%)$ & $3(5,5 \%)$ & $4(7,3 \%)$ & $1(1,8 \%)$ \\
\hline Biếng ăn & $7(12,7 \%)$ & $7(12,7 \%)$ & $8(14,5 \%)$ & $7(12,7 \%)$ & $8(14,5 \%)$ & $4(7,3 \%)$ \\
\hline Khó ngủ & $5(9,1 \%)$ & $6(10,9 \%)$ & $5(9,1 \%)$ & $5(9,1 \%)$ & $5(9,1 \%)$ & $3(5,5 \%)$ \\
\hline
\end{tabular}

Trước can thiệp (T0) nhóm can thiệp và 5,5\%); biếng ăn (12,7\% so với 14,5\%). Đến thời nhóm chứng có số lượng và tỷ lệ \% nhiễm khuẩn hô hấp, tiêu chảy, táo bón, biếng ăn, khó ngủ tương đương nhau hoặc khác biệt rất nhỏ. Sau một tháng can thiệp (T1), nhóm can thiệp đã có cải thiện hơn nhóm chứng về tỷ lệ nhiếm khuẩn hô hấp $(7,3 \%$ so với $9,1 \%)$; tiểu chảy (5,5\% so với $9,1 \%)$; táo bón $(5,5 \%$ so với điểm T2 (sau hai tháng can thiệp), sự khác biệt giữa nhóm can thiệp và nhóm chứng càng nhiều, tỷ lệ nhiễm khuẩn hô hấp (5,5\% so với $9,1 \%)$; tiêu chảy $(3,6 \%$ so với $9,1 \%)$; táo bón $(1,8 \%$ so với $7,3 \%)$; biếng ăn $(7,3 \%$ so với $14,5 \%)$; khó ngủ $(5,5 \%$ so với $9,1 \%)$. Nhưng những sự khác biệt này không có YNTK $(p>0,05)$.

Bảng 3. Tỷ lệ chấp nhận sử dụng sản phẩm sữa bột Hanie Kid

\begin{tabular}{|c|c|c|c|c|}
\hline Thời gian & Số ngày uống & Số suất sữa dự kiến & \multicolumn{2}{|c|}{ Lượng sữa uống thực tế nhóm A (n, \%) } \\
\hline Tháng 1 & 23 & 2530 & 2478 & $97,9 \%$ \\
\hline Tháng 2 & 22 & 2420 & 2372 & $98,0 \%$ \\
\hline Tống & $\mathbf{4 5}$ & $\mathbf{4 9 5 0}$ & $\mathbf{4 8 5 0}$ & $\mathbf{9 8 , 0} \%$ \\
\hline
\end{tabular}

Bảng trên cho thấy số ngày can thiệp tính của T1 là 23 ngày với 2530 suất sữa dự kiến, của T2 là 22 ngày với 2420 suất sữa dự kiến; tổng cộng 45 ngày với 4950 suất sữa nước. Trên thực tế triển khai đã sử dụng 2478 suất sữa $(97,9 \%)$ trong giai đoạn $T 1$ và 2372 suất sữa $(98,0 \%)$ cho giai đoạn T2. Trung bình đã sử dụng $98 \%$ số sữa theo kế hoạch.

Biểu đồ trên thể hiện kết quả tỷ lệ không uống sữa do các lý do khác nhau như nghỉ học, nghỉ ốm là $2,1 \%$; tỷ lệ uống không hết $1 / 2$ hộp sữa là $1,8 \%$, tỷ lệ uống đủ sữa là $96,1 \%$. Hiện tượng nôn, ói, phản ứng với sữa rất hiếm khi xảy ra.
Tỷ lệ sử dụng sữa bột Hanie Kid

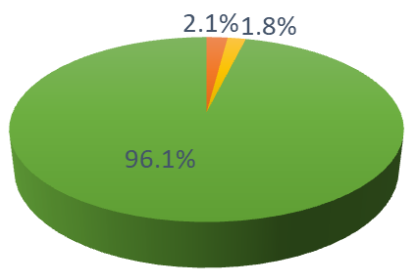

অhông uống Uống thiếu অ Uống đủ

Hình 1. Tỷ lệ chấp nhận sử dụng Sữa nước Hannie Kid 


\section{BÀN LUẬN}

Nhóm can thiệp đã cải thiện mức tăng cân ngay sau 1 tháng. Sau 2 tháng, mức tăng cân nặng nặng $0,5 \mathrm{~kg}$ và chiều cao $0,29 \mathrm{~cm}$, giảm tỷ lệ SDD, nguy cơ SDD và không có thừa cân, đồng thời có xu giảm tỷ lệ viêm đường hô hấp, tiêu chảy, táo bón, biêng ăn, khó ngủ có thể lý giải rằng nhóm đối tượng can thiệp đang thiếu dinh dưỡng trong chế độ ăn uống. Trong khi Hanie Kid đáp ứng kịp thời năng lượng và các chất dinh dưỡng như protein, lipid, carbohydrate hợp lý (khoảng $20-40 \%$ nhu câu của trẻ ở lứa tuổi này), được bổ sung thêm 28 vitamin và chất khoáng quan trọng. Các vi chất này cũng ở hàm lượng đáp ứng được khoảng $50 \%$ nhu cầu của trẻ và cân đối với nhau, do đó chúng không ảnh hưởng tới khả năng hấp thu cũng như hoạt động sinh học trong cơ thể của nhau. Trong thành phần của sản phẩm Hanie Kid, các chất dinh dưỡng như lysin, DHA, các axit amin, lipid, 28 loại vitamin, khoáng chất được bổ sung với một hàm lượng phù hợp, hỗ trợ hấp thu, chuyển hóa góp phần vào cải thiện tình trạng SDD và nguy cơ SDD [3]. Đặc biệt Lysin đã được bổ sung cho nhóm can thiệp tới $760 \mathrm{mg} / \mathrm{ngày}$ hỗ trợ cơ thể hấp thu canxi, tạo ra các mạch máu mới, tổng hợp collagen, sản sinh carnitine, giúp hấp thụ tối đa chất dinh dưỡng, sản xuất các enzyme, kháng thể và hormone, giúp cơ thể tăng cường sức đề kháng và tham gia rất nhiêu vào các quá trình chuyển hóa, giúp cơ thể phát triển, tăng miễn dịch giúp trẻ ăn ngủ ngon hơn [6]. Vitamin $A$, D, B, C, sắt, kẽm, đồng, iot, selen...tham gia chuyển hóa, tăng cường phát triển tế bào tác động đến chiều cao, cân nặng, hệ thống tiêu hóa, miễn dịch. HMO có tác dụng gần như một prebiotic tăng cường lợi khuẩn cho hệ tiêu hoá, tăng cường khả năng miễn dịch. IgG trong thành phần của sữa cho chế độ uống 2 lần/ngày có tác dụng bao phủ niêm mạc ruột làm cho nó không bị các mầm bênh thâm nhập. Các VCDD có tính chống oxy hoá có vai trò quan trọng trong việc xây dựng, tăng cường, sửa chữa hệ thống miển dịch, tăng sức đề kháng, tăng cường tiêuu hóa làm giảm biếng ăn như kẽm, selen, sắt, đồng, vitamin $A, D, C, E$, FOS [7]. DHA, Vitamin D và nhiều vi chất khác tham gia vào điều hòa thần kinh làm giảm kích thích khó ngủ. chất $x$ ơ hòa tan (FOS/Inulin) chống táo bón rất tốt. Vitamin $\mathrm{C}$, vitamin $\mathrm{B} 1$, vitamin $\mathrm{B} 2 \ldots$ giúp trẻ ăn ngon miệng tăng hấp thu, chuyển hóa, tác động đến tăng khối lượng cơ bắp, xương. Các vi chất khác tham gia vào các quá trình sinh tổng hợp hóc môn và các men, tham gia xây dựng tế bào ví dụ
B12, folic tham gia sản xuất hồng cầu, tế bào thần kinh [6]. Việc bổ sung 28 VCDD trong công thức này bồ trợ lẫn nhau có thể cho tác dụng vượt trội so với tăng cường đơn lẻ một hoặc một vài vi chất đã tác động vào hê thống tiêu hóa, miễn dịch, chuyển hóa, thần kinh thúc đẩy tăng trưởng và tăng cường sức khỏe .

Khả năng chấp nhận sử dụng cao: $96,1 \%$ số trẻ uống đủ khẩu phần sữa (2 bữa/ngày trong 2 tháng). Chương trình bổ sung sữa được gia đình, nhà trường, chính quyền, y tế ủng hộ. Tổng số đã có $98 \%$ lượng sản phẩm đã được sử dụng; Kết quả quan sát và phỏng vấn trong các chuyến giám sát ngẫu nhiên và đánh giá cho thây hầu như toàn bộ phụ huynh và cô giáo luôn ủng hộ. Công thức sữa gồm năng lượng, chất béo, protein, và 28 vitamin và khoáng chất và bố sung thêm DHA, chất xơ hòa tan (FOS/Inulin), HMO (2'-FL), Lysin, được tính theo nhu câu khuyến nghị hàng ngày của Bộ $Y$ tế và Tổ chức $Y$ tế Thế giới và tính toán từ các chuyên gia nhằm hướng tới đối tượng đích là trẻ em lứa tuổi 2-10 tuổi cũng là một yếu tố để các phụ huynh, cô giáo, cán bộ y tế ủng hộ sử dụng sản phẩm.

\section{KẾT LUÂNN}

Can thiệp bổ sung Sữa bột Hanie Kid trong 2 tháng cho học sinh lớp một cho thấy:

- Cải thiện tình trạng dinh dưỡng: cân nặng: sau 1 tháng $(0,46 \pm 0,13 \mathrm{~kg}$ so với 0,18 $\pm 0,10 \mathrm{~kg}$ ), chênh lệch $0,28 \mathrm{~kg}$, có YNTK $(p<0,05)$; sau 2 tháng $(0,93 \pm 0,3 \mathrm{~kg}$ so với 0,36 $\pm 0,17 \mathrm{~kg}$ ) chênh lệch $0,53 \mathrm{~kg}$, có YNTK $(p<0,01)$; chiêuu cao: chiều cao nhóm can thiệp có mức tăng tốt hơn nhóm chứng $(0,96 \pm 0,10$ $\mathrm{cm}$ so với $0,59 \pm 0,17 \mathrm{~cm})$, chênh lệch $0,37 \mathrm{~cm}$, có YNTK $(p<0,05)$. Làm giảm tình trạng SDD và nguy cơ SDD: SDD thể nhe cân giảm 12,7 $\%$ có YNTK $(p<0,05)$; nguy cơ SDD nhe cân giảm $14,5 \%$ có YNTK $(p<0,05)$. Không xuất hiện thừa cân, béo phì.

- Có xu hướng cải thiện tình trạng nhiễm khuẩn hô hấp, tiêu chảy, táo bón biếng ăn, khó ngủ: tỷ lệ mắc ở nhóm can thiệp thấp hơn so với nhóm chứng: nhiễm khuẩn hô hấp $(7,3 \%$; $9,1 \%)$; tiêu chảy $(6,4 \% ; 9,1 \%)$; táo bón $(4,5 \%$; $7,3 \%)$; biếng ăn $(10,9 \% ; 14,5 \%)$; khó ngủ $(7,3 \% ; 9,1 \%)$ nhưng số liệu còn ít chưa đủ làm kiểm định, không có YNTK $(p>0,05)$.

- Khả năng chấp nhận sử dụng cao: $96,1 \%$ số trẻ uống đủ khẩu phần sữa (2 bữa/ngày trong 2 tháng). Chương trình bổ sung sữa được gia đình, nhà trường, chính quyền, $y$ tế ủng hộ. 


\section{TÀI LIÊU THAM KHẢO}

1. Chính phủ (2015). Chiến lược quốc gia về dinh dưỡng giai đoan 2011 - 2020 và tầm nhìn đến năm 2030.

2. Chính phủ (2016). Chương trình sữa học đường cải thiện tình trạng dinh dưỡng góp phân nâng cao tầm vóc trẻ em mâuu giáo và tiểu học đến năm 2020.

3. Best C., Neufingerl N., Del Rosso J.M., et al. (2011). Can multi-micronutrient food fortification improve the micronutrient status, growth, health, and cognition of schoolchildren? a systematic review. Nutr Rev, 69(4), 186-204.

4. World Health Organization (2013). Essential
Nutrition Actions: improving maternal, newborn, infant and young child health and nutrition.

5. World Health Organization (2007). The new WHO child growth standards. Bull World Heal Organ, 52(1), 13-17.

6. Flodin N.w. (1997). The metabolic roles, pharmacology, and toxicology of lysine. J Am Coll Nutr, 16(1), 7-21.

7. Gombart A.F., Pierre A., and Maggini S. (2020). A Review of Micronutrients and the Immune System-Working in Harmony to Reduce the Risk of Infection. Nutrients, 12(1), 123-133.

\section{THAY ĐỔI GIÁ TRI qHBsAg Ở BỆNH NHÂN VIÊM GAN VI RÚT B MẠN KHI ĐIỀU TRI BẰNG TENOFOVIR DISOPROXIL FUMARATE HOĂC TENOFOVIR ALAFENAMIDE}

\section{TÓM TẮT}

Mục tiêu: Khảo sát sự thay đổi qHBsAg ở bệnh nhân (BN) HBV man điểu trị tenofovir disoproxil fumarate (TDF) hoắc tenofovir alafenamide (TAF). Đối tượng và phương pháp nghiên cứu: Nghiên cứu cắt ngang mô tả thực hiện trên những $\mathrm{BN} H B V$ man điều trị ngoại trú với TDF 300mg hoặc TAF 25mg tại phòng khám Viêm gan ,bênh viện Đại học Y Dước TiP Hồ Chí Minh từ tháng 01/2017 đến 12/2020. Tiển hành đánh giá sự thay đổi qHBsAg khi điều trị với TDF hoăc TAF. Kết quả: Nghiên cứu có 250 BN, trong đó $160 \mathrm{BN}(64 \%)$ được điều trị với TDF và 90 BN (36\%) được điều trị TAF. Thời gian điều trị trung bình của nhóm TDF là 4,1 năm và ở nhóm TAF là 2,5 năm. Giá trị qHBsAg trung bình tại thời điểm bắt đầu nghiên cứu của nhóm $B N$ điều trị TDF là $3,0 \pm 0,8\left(\log _{10}\right.$ $\mathrm{UI} / \mathrm{ml}$ ) cao hơn có ý nghĩa so với nhóm BN đang điêu trị TAF $(2,7 \pm 0,9$ với $p=0,02)$. Trong nhóm điêuu trị với TDF, giá trị qHBsAg trung bình sau 12 tuần giảm không có ý nghĩa thống kê so với thời điểm bắt ( $p=$ $0,2)$ nhưng giảm có ý nghĩa tại thời điểm 24 tuần so với ban đầu $(p=0,02)$. Ớ nhóm điều trị với TAF, giá trị qHBsAg giảm không có ý nghĩa ở thời điểm sau 12 tuần $(p=0,8)$ và 24 tuần $(p=0,4)$. Kết luân: Nghiên cứu cho thấy giá trị qHBsAg giám có ý nghĩa tại thời điểm 24 tuần trong quá trình điều trị TDF, tuy nhiên giá trị qHBsAg giảm không có ý nghĩa trong quá trình điều trị TAF thời gian ngắn. Cần có nhiều nghiên cứu với cỡ mẫu lớn hơn, đa trung tâm và thời gian theo dõi dài hơn đến đánh giá vai trò của thuốc tới sự thay đổi qHBsAg.

Tư khoá: qHBsAg, Viêm gan B mạn, TDF, TAF

\footnotetext{
${ }^{1}$ Đại học Y Dược Thành phố Hồ Chí Minh Bềnh viên Chơ Rẫy, Thành phố Hồ Chí Minh Chịu trách nhiệm chính: Võ Duy Thông Email: duythong@ump.edu.vn Ngày nhận bài: 9.4.2021

Ngày phản biên khoa hoc: 24.5.2021

Ngày duyệt bài: 9.6.2021
}

Võ Duy Thông1,2, Võ Ngọc Diễm ${ }^{1}$

\section{SUMMARY \\ CHANGE OF qHBsAg VALUE IN CHRONIC HEPATITIS B PATIENTS TREATED WITH TENOFOVIR DISOPROXIL FUMARATE OR TENOFOVIR ALAFENAMIDE}

Objectives: To investigate the change in qHBsAg in chronic HBV patients treated with tenofovir disoproxil fumarate (TDF) or tenofovir alafenamide (TAF). Methods: A descriptive cross-sectional study was conducted on chronic HBV outpatients treated with TDF $300 \mathrm{mg}$ or TAF $25 \mathrm{mg}$ at the Hepatitis clinic, Ho Chi Minh City University of Medicine and Pharmacy Hospital from January 2017 to December 2020. The qHBsAg change was evaluated in patients treated with TDF or TAF. Results: There were 250 patients included in this study, of which 160 patients (64\%) were treated with TDF and 90 patients (36\%) with TAF. The mean duration of treatment in the TDF group was 4.1 years and in the TAF group was 2.5 years. The mean baseline qHBsAg value in TDF group $(3.0 \pm 0.8(\log 10 \mathrm{UI} / \mathrm{ml}))$ was significantly higher than that in TAF group $(2.7 \pm 0.9), p=0.02$. In the TDFtreated group, the mean qHBsAg value at 12 weeks was not significantly different, compared to that at baseline $(p=0.2)$, but the qHBsAg decreased significantly at 24 weeks $(p=0.02)$. In the TAFtreated group, the mean $\mathrm{qHBsAg}$ value was not significantly diferent at 12 weeks $(p=0.8)$ and 24 weeks $(p=0.4)$ compared to baseline one. Conclusion: The study showed that qHBsAg value decreased significantly at 24 weeks during TDF treatment. However, qHBsAg value did not decrease significantly during short-term TAF treatment. More studies with larger sample sizes, multicenters and longer follow-up are needed to evaluate the effectiveness of drugs in the change of qHBsAg.

Keywords: qHBsAg, Chronic Hepatitis B, TDF, TAF

\section{I. ĐĂT VẤN ĐỀ}

Theo báo cáo của Tổ chức y tễ thế giới vào 